\title{
Pengaruh Pengetahuan Terhadap Sikap Ibu Mengenai Imunisasi Ulangan Difteria-Tetanus
}

\author{
Yenny Purnama, Eddy Fadlyana, Nanan Sekarwana \\ Bagian Ilmu Kesehatan Anak Fakultas Kedokteran Universitas Padjadjaran/Rumah Sakit Dr. Hasan \\ Sadikin Bandung
}

\begin{abstract}
Latar belakang. Peran serta dan penerimaan ibu mengenai imunisasi ulangan difteria-tetanus diperlukan untuk menunjang upaya pencegahan penyakit tersebut.

Tujuan. Mengetahui pengaruh pengetahuan terhadap sikap ibu murid SD kelas I mengenai imunisasi ulangan difteria-tetanus.

Metode. Subjek penelitian adalah ibu murid SD kelas I di Kotamadya Bandung, menggunakan penelitian kuantitatif dan kualitatif. Rancangan penelitian kuantitatif berupa survei cross-sectional dimulai bulan November sampai Desember 2007. Sampel diambil secara cluster random sampling. Analisis statistik dilakukan untuk melihat pengaruh pengetahuan ibu murid SD kelas 1 terhadap sikap imunisasi ulangan difteria-tetanus dengan menggunakan analisis jalur. Pengetahuan adalah informasi yang dimiliki oleh ibu mengenai penyebab, gejala, pengobatan, penularan, dan pencegahan tentang penyakit difteria-tetanus. Sikap adalah respons ibu terhadap penyakit difteria-tetanus mengenai penyebab, gejala, pengobatan, penularan, dan pencegahannya. Rancangan penelitian kualitatif berupa focus group discussion dengan analisis deskriptif, untuk menilai pengetahuan dan sikap ibu mengenai imunisasi ulangan difteria-tetanus yang tidak tergali dengan penelitian kuantitatif. Sampel diambil sebanyak 5-10 orang dari ibu yang telah ikut dalam penelitian kuantitatif.

Hasil. Didapatkan 226 ibu dengan rata-rata usia 35 tahun. Hasil analisis jalur, didapatkan pengetahuan secara signifikan dipengaruhi oleh pendidikan ibu dan jumlah anak. Sikap signifikan dipengaruhi oleh pendidikan ibu dan pengetahuan $(95 \% \mathrm{CI}:-\mathrm{t}<+1,96>\mathrm{t})$. Hasil analisis jalur didapatkan pengaruh total pendidikan ibu dan pengetahuan terhadap sikap adalah cukup. Pengaruh total pendidikan ibu dan jumlah anak terhadap pengetahuan adalah kurang. Analisis focus group discussion tergambarkan bahwa ibu yang mempunyai pengetahuan tinggi lebih bersikap mandiri terhadap pelaksanaan imunisasi ulangan difteria-tetanus.

Kesimpulan. Pengetahuan ibu berpengaruh positif terhadap sikap ibu mengenai imunisasi ulangan difteriatetanus (Sari Pediatri 2008;10(2):117-121).
\end{abstract}

Kata kunci: pengetahuan, sikap, imunisasi, difteria-tetanus

\footnotetext{
Alamat Korespondensi:

Dr. Yenny Purnama, SpA, Bagian Ilmu Kesehatan Anak Fakultas Kedokteran Universitas Padjadjaran/Rumah Sakit Dr. Hasan Sadikin Jl. Pasteur No. 38 Bandung 40163, Indonesia.

Telp. 022-2035957. E-mail: yennypurnama@yahoo.com.
} 
S elama beberapa tahun terakhir ini terjadi kekhawatiran akan timbulnya kembali beberapa penyakit penyakit menular, seperti difteria dan tetanus. ${ }^{1}$ Program imunisasi melalui the expanded program on immunization (EPI), seharusnya sudah menjadikan kedua penyakit tersebut jarang ditemukan di dunia, namun menurut laporan WHO pada tahun 2007 didapatkan kasus penyakit difteria 3.966, tetanus 13.689, dan tetanus neonatorum 8.377 orang. ${ }^{2}$ Laporan distribusi penyakit difteria dan tetanus yang didapatkan dari buku profil kesehatan Jawa Barat tahun 2005 di Jawa Barat, ditemukan kasus difteria, tetanus, dan tetanus neonatorum berturutturut 80, 76, dan 39 orang. ${ }^{3}$ Pengembangan Program Imunisasi (PPI) di Indonesia yang dilaksanakan mulai tahun 1979 (awal PELITA III) menghadapi masalah yang sama dengan yang dijumpai di berbagai negara di dunia, yaitu angka cakupan imunisasi yang rendah dan angka drop-out kunjungan ulangan yang tinggi. Salah satu faktor penyebab kegagalan program imunisasi adalah penolakan ibu terhadap imunisasi. ${ }^{4}$ Penolakan imunisasi antara lain diakibatkan oleh anggapan salah tentang imunisasi yang berkembang dalam masyarakat, banyak pula orangtua dan kalangan praktisi tertentu khawatir terhadap risiko dari beberapa vaksin. ${ }^{5}$ Adapula media yang masih mempertanyakan manfaat imunisasi serta membesar-besarkan risiko beberapa vaksin. Penelitian Davies $\mathrm{dkk}^{6}$ mendapatkan $43 \%$ situs yang ada di internet merupakan situs antivaksinasi.

Beberapa studi mendapatkan bahwa usia ibu, ras, pendidikan, dan status sosial ekonomi berhubungan dengan cakupan imunisasi, ${ }^{7}$ serta opini orangtua tentang vaksin berhubungan dengan status imunisasi anak mereka. ${ }^{8}$ Penggunaan sarana kesehatan oleh anak, berkaitan erat dengan perilaku dan kepercayaan ibu tentang kesehatan dan hal ini akan mempengaruhi status imunisasi anaknya. ${ }^{7}$ Tujuan penelitian untuk mengetahui pengaruh pengetahuan terhadap sikap ibu murid SD kelas I mengenai imunisasi ulangan difteria-tetanus.

\section{Metode}

Penelitian kuantitatif dengan rancangan penelitian cross sectional. Pengambilan sampel dilakukan dengan cara cluster random sampling pada semua ibu murid kelas I SD di Kotamadya Bandung yang terpilih. Ibu yang menyetujui setelah informed consent diminta un- tuk menandatangani surat persetujuan. Pengambilan sampel dilakukan bulan November sampai Desember 2007. Semua subjek penelitian yang memenuhi kriteria inklusi dicatat indentitasnya, meliputi nama, usia, tingkat pendidikan ibu, pekerjaan ibu, agama ibu, suku bangsa ibu, usia suami, tingkat pendidikan suami, pekerjaan suami, agama suami, suku bangsa suami, jumlah anak, dan penghasilan keluarga. Untuk menguji kesahihan alat ukur dalam penelitian ini digunakan korelasi Pearson dan untuk menguji keterandalan alat ukur digunakan paket program Uji Keterandalan teknik Alpha Crombach, serta proses pengujiannya dilakukan dengan menggunakan SPSS. Dari hasil pengujian kesahihan dan keterandalan didapatkan pernyataan sebanyak 58 dari 70 butir, diuji cobakan kepada $37 \mathrm{ibu}$. Data yang diperoleh, dicatat, dan ditabulasi. Oleh karena tujuan penelitian menguji hipotesis mengenai pengaruh variabel penunjang dan variabel pengetahuan terhadap variabel sikap, maka analisis statistik dilakukan dengan menggunakan analisis jalur, melalui metode successive interval, dengan bantuan program LISREL 8.5. Pengetahuan adalah informasi yang dimiliki oleh ibu mengenai penyebab, gejala, pengobatan, penularan, dan pencegahan tentang penyakit difteria-tetanus. Sikap adalah respons ibu terhadap penyakit difteria-tetanus mengenai penyebab, gejala, pengobatan, penularan, dan pencegahannya.

Penelitian kualitatif, dengan rancangan penelitian berupa focus group discussion (FGD), dengan analisis deskriptif. Penelitian kualitatif dilakukan untuk menilai pengetahuan dan sikap ibu mengenai imunisasi ulangan difteria-tetanus yang tidak tergali dengan penelitian kuantitatif. Peneliti dibantu oleh seorang psikolog melakukan FGD. Subjek penelitian 5-10 orang didapat dari ibu yang telah ikut penelitian kuantitatif.

\section{Hasil}

Dari data penelitian didapatkan 226 orang ibu yang memenuhi kriteria penelitian, sedangkan 10 orang dikeluarkan dengan alasan tidak mengisi kuesioner dengan lengkap. Pekerjaan ibu terbanyak adalah ibu rumah tangga dan terbanyak berpendidikan menengah, serta berpenghasilan rendah. Karakteristik umum ibu tertera pada Tabel 1.

Rata-rata nilai pengetahuan 11,96 dengan rentang nilai terendah 0 dan tertinggi 18 . Untuk rata-rata nilai 
Tabel 1. Karakteristik ibu yang menjadi subjek penelitian

\begin{tabular}{|c|c|}
\hline Karakteristik & \\
\hline Usia (tahun) & \\
\hline Termuda & 20 \\
\hline Tertua & 55 \\
\hline Median & 35 \\
\hline Pekerjaan (\%) & \\
\hline PNS & $15(6,7)$ \\
\hline Pegawai swasta & $23(10,2)$ \\
\hline Buruh & $22(9,6)$ \\
\hline Wiraswasta & $20(8,8)$ \\
\hline Guru & $8(3,5)$ \\
\hline Profesi & $2(1,0)$ \\
\hline Ibu rumah tangga & $136(60,2)$ \\
\hline Pendidikan (\%) & \\
\hline Tinggi & $27(12,0)$ \\
\hline Menengah & $121(53,4)$ \\
\hline Rendah & $78(34,6)$ \\
\hline Suku bangsa (\%) & \\
\hline Sunda & $189(83,4)$ \\
\hline Jawa & $24(10,6)$ \\
\hline Padang & $4(1,9)$ \\
\hline Batak & $2(1,0)$ \\
\hline Lain-lain & $7(3,1)$ \\
\hline Penghasilan keluarga (\% & \\
\hline Rendah & $106(47,0)$ \\
\hline Menengah & $46(20,4)$ \\
\hline Tinggi & $74(32,6)$ \\
\hline Jumlah anak (\%) & \\
\hline Satu & $57(25,2)$ \\
\hline Dua & $102(45,1)$ \\
\hline Tiga & $48(21,2)$ \\
\hline Empat & $13(5,8)$ \\
\hline Lima & $6(2,7)$ \\
\hline
\end{tabular}

sikap adalah 157,67 dengan rentang nilai terendah 95 dan tertinggi 200. Pengetahuan ibu tinggi, sedang, dan rendah berturut-turut 30,8\%, 35,4\%, dan 43,8\%. Presentasi sikap ibu sangat positif, positif, negatif, dan sangat negatif berturut-turut 31,$1 ; 51,7 ; 15,1$; dan $2,2 \%$.

Analisis jalur dilakukan menggunakan program LISREL 8.5 dengan model pengaruh dari variabel umur ibu, pekerjaan ibu, pendidikan ibu, usia suami, pekerjaan suami, pendidikan suami, penghasilan suami, jumlah anak yang dimiliki, serta pengetahuan tentang imunisasi dan sikap terhadap imunisasi dapat dilihat pada diagram jalur berikut (Gambar 1). Berdasarkan jalur variabel bebas terhadap variabel tergantung diperoleh hasil variabel penunjang yang berpengaruh terhadap pengetahuan adalah jumlah anak dengan nilai statistik uji $\mathrm{t}=-3,43$, pendidikan ibu memberikan pengaruh terhadap sikap dengan nilai statistik uji $t=3,21$, pengetahuan berpengaruh terhadap sikap dengan nilai statistik uji $t=10,58$. Hasil pengujian adanya pengaruh dikatakan signifikan karena memiliki nilai statistik uji yang lebih besar dari 1,96 pada taraf nyata $\alpha=5 \%$.

Pengetahuan secara signifikan dipengaruhi oleh pendidikan ibu dan jumlah anak dengan nilai statistik uji yang lebih besar dari 1,96 pada taraf nyata 5\% yaitu 4,57 dan $-3,16$. Sikap secara signifikan ternyata dipengaruhi oleh pendidikan ibu dan pengetahuan yang menunjukkan nilai statistik uji masing-masing 3,48 dan 11,45 .

Hasil focus group disscusion dilakukan pada dua sekolah yaitu MI Miftahul Falah dan SDN Sejahtera dengan jumlah peserta masing-masing 8 orang dan 11 orang. Pada kelompok MI Miftahul Falah, pengetahuan tentang penyakit difteria dan tetanus

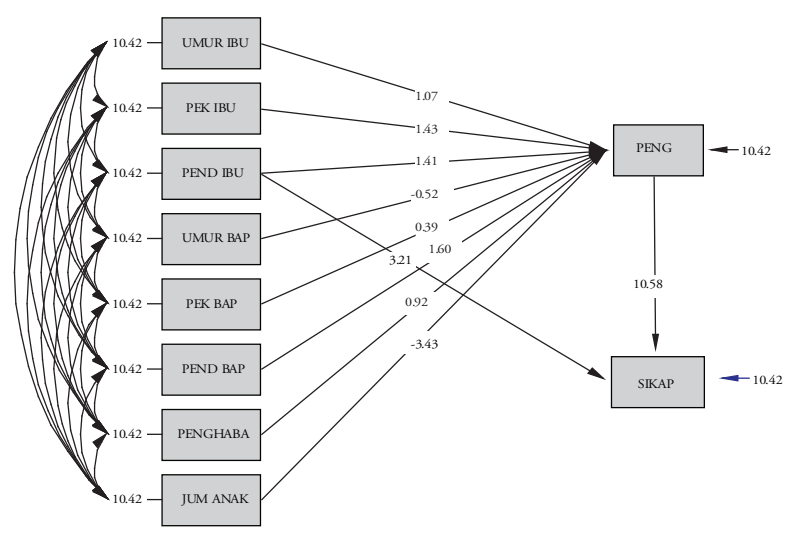

Chi-Square $=9.87, \mathrm{df}=7, \mathrm{P}-$ value $=0.19620$, RMSEA $=0.043$

Gambar 1. Hasil analisis jalur bersama penelitian Model pengaruh dapat disederhanakan, dengan hanya mengikutkan variabel yang signifikan (Gambar 2).

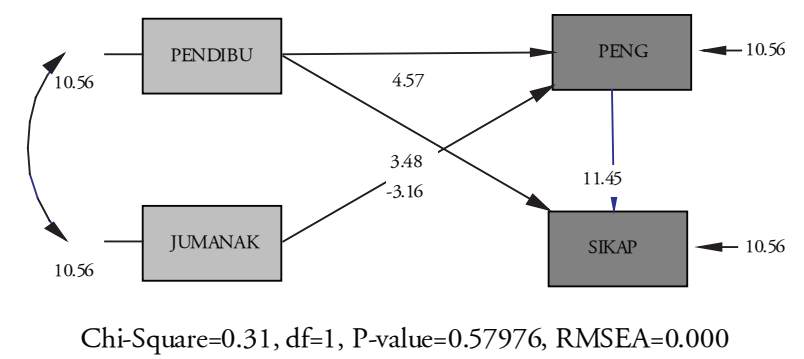

Gambar 2. Hasil analisis jalur individu penelitian 
sangat terbatas, baik mengenai gejala penyakit maupun penyebabnya. Berdasarkan sumber pengetahuan, terlihat bahwa pengetahuan tersebut diperoleh melalui cerita turun temurun dari ibu mereka dan pada beberapa orang pengetahuan tersebut diperoleh karena pernah mengalami keterlibatan dengan orang yang menderita penyakit tersebut. Sedangkan kelompok ibu-ibu murid SD Sejahtera menunjukkan pengetahuan yang lebih baik tentang penyakit difteria dan tetanus dibandingkan dengan kelompok ibu-ibu MI Miftahul Falah. Sumber informasi yang dijadikan rujukan kelompok ibu SD Sejahtera mendapatkan pengetahuan tentang penyakit difteria dan tetanus dari dokter/perawat Posyandu, penyuluhan pra-nikah, poster di rumah sakit, internet, dan di buku pelajaran IPA SD kelas 5 milik putranya.

\section{Pembahasan}

Karakteristik responden menunjukkan usia ibu relatif muda, sebagian besar ibu rumah tangga, pendidikan menengah, dan jumlah anak satu dan dua orang, hal ini menunjukkan bahwa responden berpotensi untuk mendapat peluang mencari pengetahuan lebih banyak, baik secara waktu yang terluang, ketidak-sibukan, dan kemampuan intelektual. Responden mempunyai pengetahuan mengenai difteria dan tetanus di atas rata-rata dan bersikap positif.

Hasil analisis jalur ditemukan tiga hal yang mempengaruhi sikap yaitu pendidikan ibu, jumlah anak, dan pengetahuan ibu. Berdasarkan pemikiran bahwa pendidikan adalah suatu upaya seseorang untuk mendapatkan pengetahuan secara formal. Pendidikan formal mengajarkan berbagai hal pengetahuan. Pengetahuan tentang penyakit difteria dan tetanus meliputi penyebab, penularan, gejala, akibat yang ditimbulkan, pengobatan, dan cara pencegahannya, bisa didapatkan dari pendidikan formal, sehingga hal ini akan mempengaruhi sikap ibu terhadap imunisasi difteria dan tetanus secara langsung dan tidak langsung. ${ }^{9}$ Hasil penelitian, sejalan dengan hasil penelitian yang dilakukan oleh Idwar. ${ }^{10}$ Jumlah anak yang semakin banyak akan mengakibatkan perhatian ibu terhadap suatu masalah akan semakin kurang. ${ }^{11}$ Demikian halnya dengan masalah imunisasi difteria dan tetanus, ibu akan lebih memperhatikan tentang pemanfaatan penghasilan, pemenuhan gizi, sekolah, dan lain-lain. ${ }^{12}$ Pengetahuan yang semakin tinggi akan semakin mempengaruhi sikap ibu tentang pentingnya imunisasi difteria dan tetanus. ${ }^{13,14}$ Pengetahuan tentang kedua penyakit tersebut akan mendorong ibu untuk mencari pencegahan yang paling efektif, aman, dan mudah dilakukan, sesuai dengan tujuan imunisasi adalah suatu tindakan yang mudah, aman, dan efektif dalam pencegahan penyakit. ${ }^{15}$ Penemuan tersebut sejalan dengan penelitian yang dilakukan Doren $\mathrm{dkk}^{7}$ dan Idwar. ${ }^{10}$

\section{Focus group discusion}

Berdasarkan pengetahuan ibu murid MI Miftahul Falah yang bersumber dari kedua hal tersebut (cerita turun temurun dan kebetulan), maka kebenaran substansi maupun pemanfaatan pengetahuannya akan lebih kecil kemungkinan terjadinya, dibandingkan dengan pengetahuan yang diperoleh secara sengaja oleh orang yang bersangkutan. ${ }^{9,11}$ Dengan demikian, ketergantungan benar/salah dari pengetahuan maupun tindakannya akan tergantung pada lingkungannya. Demikian pula dengan sikapnya terhadap sesuatu, akan cenderung berkembang sesuai dengan sikap orang lain di sekelilingnya. ${ }^{9}$ Dalam konteks imunisasi yang telah dilakukan, kita tidak bisa berharap bahwa kelompok informan ini akan secara mandiri mengupayakan pencegahan yang diperlukan dalam hal kesehatan bagi anggota keluarga mereka, karena mereka akan bersikap sesuatu atau melakukan sesuatu hanya jika ada orang lain (figur signifikan, tokoh masyarakat, atau orang yang disegani) melakukannya atau menekan mereka untuk melakukannya.

Pengetahuan ibu murid SD Sejahtera tentang gejala penyakit, dan akibatnya, serta cara pencegahannya, merupakan faktor yang memberi kontribusi bagi kesediaan mereka untuk melakukan pencegahan agar anaknya tidak terjangkit penyakit tersebut. Seluruh anggota kelompok informan yang pernah mendapatkan anjuran dari dokter/perawat/bidan pada saat anaknya diimunisasi sewaktu bayi, bahwa sebaiknya imunisasi diulang lagi setelah anak berusia enam tahun, menunjukkan adanya pengetahuan yang mendukung munculnya sikap positif terhadap imunisasi. ${ }^{13}$ Kecenderungan afeksi yang positif terhadap imunisasi juga ditunjukkan oleh kelompok ibu SD Sejahtera, melalui pernyataan mereka bahwa meski hanya berupa pemberitahuan dan bukan anjuran, mereka secara sukarela mengizinkan anaknya untuk diimunisasi, yang didasari oleh pengetahuan 
mereka akan pentingnya hal tersebut.

Pada kelompok ibu SD Sejahtera dapat diharapkan bahwa mereka dapat diandalkan untuk secara mandiri melakukan pencegahan bagi anggota keluarga mereka agar tidak terjangkit penyakit-penyakit tersebut, termasuk melakukan imunisasi. ${ }^{13}$ Kemandirian tersebut tampil pula dalam situasi diskusi mereka terhadap kebenaran informasi atau pengetahuan yang mereka miliki dan sikap yang tidak mudah terpengaruh oleh orang lain. ${ }^{15}$

\section{Kesimpulan}

Hasil penelitian menunjukkan pengaruh positif pengetahuan terhadap sikap ibu murid kelas I SD mengenai imunisasi ulangan difteria dan tetanus. Pengetahuan yang baik akan meningkatkan sikap positif ibu untuk secara mandiri melakukan imunisasi ulangan difteria dan tetanus pada anaknya. Hal ini akan menjadi salah satu dasar untuk meningkatkan pengetahuan sebelum melakukan program imunisasi pada masa yang akan datang melalui sarana, prasarana dan sesuai dengan keminatan masyarakat masingmasing daerah.

\section{Daftar Pustaka}

1. Keputusan Menteri Kesehatan Republik Indonesia. Pedoman penyelenggaran imunisasi. Nomor 1059/ MENKES/SK/IX/2004.

2. WHO 2007. Incidence series (diunduh 15 Agustus 2007). Tersedia dari: http://www.who. /phd/ immunization/

3. Profil kesehatan Provinsi Jawa Barat 2005. Bandung: Depkes Jabar; 2006.

4. Bedford H, Elliman D. Concern about immunization. Brit Med J. 2000;45:1081-9.

5. American Academy of Pediatrics, Division of Health Policy Research. Periodic survey of fellow no.48: Immunization
Administration Practices. AAP. 2001:1-9.

6. Davies P, Chapman S, Leask J. Antivaccination activitists on the world wide web. Arch Dis Child 2002;87:22-5.

7. Doren DF, Terry CD, Connie LA, Esatela MK, Sharon GH, Thomas JC, dkk. Chilhood immunization refusal: provider and parent perceptions. Fam Med 2004;36:431-9.

8. Douglas SD, Committee on Bioethics. Responding to parental refusal of immunization of children. Pediatrics 2005;115:1-11.

9. Notoatmojo S. Promosi kesehatan dan ilmu perilaku. Edisi ke-satu. Jakarta: PT Rineka Cipta; 2007. h.13346.

10. Idwar. Faktor-faktor yang berhubungan dengan status imunisasi hepatitis B pada bayi (0-11 bulan) di Kabupaten Aceh Besar Propinsi istimewa Aceh tahun 1998/1999 (diunduh 21 November 2007). Tersedia dari: http:/digilib.litbang.depkes.go.id/

11. Masjkuri NM. Ibu-ibu yang tidak tahu tentang imunisasi: ciri-ciri dan kegiatannya yang dapat dipakai sebagai sarana pemberian informasi. Medika 1985;9:842-4.

12. Akhmad S. Pola relasi orangtua-anak dan pengaruhnya terhadap perkembangan anak (diunduh 11 Juli 2007). Tersedia dari: http//www.us.else vierhealth.com/product. jsp?isbn=0721696880

13. Muhammad A. Pengetahuan, sikap dan perilaku ibu bekerja dan tidak bekerja tentang imunisasi. Bagian IKA Fakultas Kedokteran Universitas Sumatera Utara (diunduh 20 Agustus 2007). Tersedia dari: http//www. usu.library.2003/

14. Barbara B, Idalia MG, Michael LW, Beth PB, Francisco A, Mehran SM, dkk. Parental knowledge, attitudes, and practices associated with not receiving hepatitis A vaccine a demonstration project in butte country, California. Pediatrics 2003;112:e269-74.

15. Lubis IZ, Lubis M, Loebis MS, Manoeroeng SM, Lubis CP. Pengetahuan, sikap, dan perilaku orangtua tentang imunisasi. Edisi khusus: Maj Kedok Nusantara 1990;1:111. 